\title{
Laser Micro Dissection Systems: An Alternative Method of Defined Cell Isolation for Molecular Profiling
}

\author{
Ratan K Choudhary* \\ School of Animal Biotechnology, Guru Angad Dev Veterinary and Animal Science University, Ludhiana- 141004, Punjab, India
}

Submission: October 01, 2016; Published: January 03, 2017

*Corresponding author: Ratan K Choudhary, School of Animal Biotechnology, Guru Angad Dev Veterinary and Animal Science University, Ludhiana- 141004, Punjab, India; Email address: vetdrrkc@gmail.com

\begin{abstract}
Laser micro-dissection permits isolation groups of cells from heterogeneous tissue sections under direct microscopic visualization. This technology not only allows isolation of homogenous subpopulation of cells but also allows immunophenotypically similar cells for RNA/ DNA or protein extraction for downstream applications like western blot, mass spectrophotometry, real time quantitative polymerase chain reaction, microarray and RNA sequencing. Isolation of dead cells unsuitable for functional assays, high cost of equipment and technical expertise required for operation are few limitations to laser microdissection systems.

Keywords: Laser microdissection; mammary tissue; carcinoma; immunolabelled cell; transcriptomics; proteomics

Abbreviations: LMD: Laser microdissection;LCM:Laser capture microdissection; UV: Ultraviolet; IR: Infrared rays; PEN:Polyethylene naphthalate; PPS:polyphenylenesulphide; RNAseq: RNA sequencing; BrdU:bromodeoxyuridine; qPCR: quantitative polymerase chain reaction; xMD:expression microdissection; 2D: Two dimensional; iTRAQ: Isobaric tag for relative and absolute quantitation; LREC: Label retaining epithelial cells
\end{abstract}

\section{Introduction}

\section{Principles of laser microdissection systems}

There are two types of laser based micro dissection systems, ultra-violet (UV) and Infrared (IR) laser based systems. IR laser micro dissection system transfers cells into thermoplastic polymer (called "capture) from which molecules are extracted for downstream applications. Therefore, this system is called laser capture micro dissection (LCM) system. The principle of LCM is depicted in which tissue sections are placed on the stage of microscope. Thermoplastic sheet (a transparent ethylene vinyl acetate layer, usually $6 \mathrm{~mm}$ in diameter) is placed onto the tissue section. When IR laser beam is focussed, thermoplastic sheet just above the tissue section melts and surrounds (i.e. captures) the tissue/cells of interest $[1,2]$. Later on thermoplastic sheet, embedded tissue/cells are harvested in a tube's cap for nucleic acids or protein isolation for downstream applications. Initially, this technique was applicable on the frozen tissue sections [3]. Later on, this technique is used on formalin fixed, paraffin embedded tissue sections, smears, cytospins, live cells for RNA, DNA or protein isolations $[4,5]$.
Laser micro-dissection (LMD) is UV laser based system where tissue sections are placed on glass membrane slides. Polyethylene naphthalate (PEN) or polyphenylene sulphide (PPS) membranes are cemented onto glass slides, commonly called glass membrane slides. Tissue sections placed on the top of the membrane and slides are kept inverted, facing tissue sections downwards towards collector. When UV laser passed from upward passes through the glass slides, it cuts the membrane. The areas of interest are selected on computer screen and membranes associated with area of interest are deposited into collector through gravity. Unfortunately, UV laser damages the molecules that comes in the cut perimeter especially when area of interests are very small like single cell.

The combination of IR laser capture and UV laser cutting (Arcturus $\mathrm{XT}^{\mathrm{TM}}$ micro dissection system, from Life Technology, as an example) is really a promising one to perform both types of work under the same platform. Three different types of laser micro-dissection systems include, IR laser system, UV laser system and combined laser systems (Table 1). In this review, 
usefulness LMD on isolation of different type of cells, in particular mammary tissue, including isolation of pathogens from the tissue section, has been discussed. Author believes that there is not much reviews focussed on application of LMD for isolation of various types of cells from complex tissue in veterinary and animal sciences are present. Furthermore, molecular profiling such as RNA seq or proteomics study of micro dissected cells would certainly provide insights of biology of harvested cells from their tissue.

Table 1: Various types of laser microdissection systems and their characteristic of tissue/cell isolation.

\begin{tabular}{|c|c|c|c|}
\hline $\begin{array}{l}\text { Types of Laser } \\
\text { microdissection system }\end{array}$ & $\begin{array}{l}\text { Name of Laser } \\
\text { microdissection system }\end{array}$ & Vendors & Properties \\
\hline $\begin{array}{l}\text { Infra-red (IR) laser } \\
\text { capture system }\end{array}$ & PixCell II & Arcturus & $\begin{array}{l}\text { A laser capture microdissection (LCM) system, utilizes low- } \\
\text { power infrared laser to melt a thermoplastic film over the } \\
\text { cells of interest. Caps are collected with adherent target cells. }\end{array}$ \\
\hline \multirow{3}{*}{$\begin{array}{l}\text { Ultra-violet (UV) laser } \\
\text { microdissection system }\end{array}$} & Laser microdissection & Leica & $\begin{array}{c}\text { A laser microdissection system utilizes ultra-violet light } \\
\text { to melt thin film over the tissue or interest. Contact and } \\
\text { contamination free method, as isolated cells are falls into } \\
\text { collector by gravity. }\end{array}$ \\
\hline & PALM Microbeam & Zeiss & $\begin{array}{l}\text { A non-contact sampling method that combines laser } \\
\text { microdissection and pressure catapulting technology, a laser } \\
\text { assisted transfer of sample. }\end{array}$ \\
\hline & MMI-CellCut Plus & $\begin{array}{l}\text { Molecular Machines } \\
\text { and Industries } \\
\text { (MMI) }\end{array}$ & $\begin{array}{l}\text { Tissue section is sandwiched between membrane slide and } \\
\text { glass slide. UV laser is passed through glass slide that cuts } \\
\text { the tissue/cell of interest along with the membrane. Lifting } \\
\text { adhesive caps of collector collects isolated target area. }\end{array}$ \\
\hline $\begin{array}{l}\text { Combined IR and UV laser } \\
\text { systems }\end{array}$ & $\begin{array}{l}\text { - Veritas } \\
\text { - Arcturus XT }\end{array}$ & Arcturus & $\begin{array}{l}\text { This system applies powers of two lasers, gentle infrared } \\
\text { laser for cutting and UV laser for capturing harvested cells. }\end{array}$ \\
\hline
\end{tabular}

In this review, usefulness LMD on isolation of different type of cells, in particular mammary tissue, including isolation of pathogens from the tissue section, has been discussed. Author believes that there is not much reviews focussed on application of LMD for isolation of various types of cells from complex tissue in veterinary and animal sciences are present. Furthermore, molecular profiling such as RNAseq or proteomics study of microdissected cells would certainly provide insights of biology of harvested cells from their tissue.

\section{Isolation and molecular profiling of defined cells from tissue}

\section{Mammary epithelial cells and stroma}

Information on use of laser micro dissection system to characterize mammary tissue is limited. Mammary tissue is composed of mammary epithelium and stroma embedded in the adipose tissue. Isolation of epithelial cells and stroma individually could provide unique and common characteristics of mammary epithelial cells and stroma, respectively that could provide reliable cell-specific gene expression and functions. Considering that RNA quality decides transcriptomic analysis of tissue harvested after micro dissection, it is important to process frozen section quickly. Staining of frozen sections using haematoxylin or cresyl violet or fast red or toluidine blue stains in nuclease free conditions provided isolation of good quality RNA from mammary epithelium and stroma [6-10] (Figure 1AC).

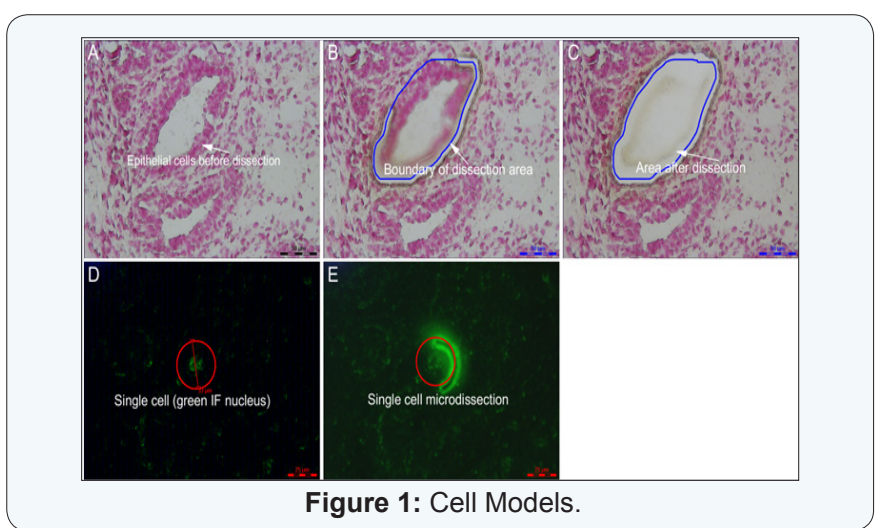

Laser micro dissection also permitted investigators to study the immune-modulatory role of mammary epithelial cells during mastitis. In goats, mammary gland (one quarter) infected with pathogens while the other half gland (other quarter) served as control. Mammary epithelial cells were dissected out leaving contaminating inflammatory cells. Investigators examined epithelial cells specific gene expression profiles [13]. In addition 
to the transcriptomic analysis of micro dissected mammary tissues using microarray and real time qPCR, RNA Sequencing (RNA seq) also examined gene profile [14]. RNA seq is the advent of next generation sequencing that offer more advantages over microarray because of its ability to identify all genes including novel gene, splice variants, allele-specific expression, independent of genome annotation and absolute quantification of copy numbers transcripts $[15,16]$.

\section{Nerve cells}

Molecular analysis of class specific neuronal development requires identification of pure population of class specific neurons. Identification and isolation of pure population of peripheral neurons that were performed using magnetic bead sorting [17] and florescent activated cell sorting did not procure accurate isolation of specific cells. However, laser capture micro dissection provided accurate and precise isolation of dendritic neurons, motor nerves, dopaminergic, catecholamine neurons and astrocytes for understanding molecular mechanism of classspecific dendrite morphogenesis and progression of disease like Parkinson's [18-26]. Identification of similar cells that differs immune phenol typically coupled with laser micro dissection enabled RNA isolation [3,1][27-30] for gene expression analysis like qPCR. Alternatively, in thin serial sections, parvalabumin neurons were identified immune histo chemically in one section and adjacent sections simply stained with neutral red.

In neutral red sections, Neuronal profiles of parvalbumin immune stained section identified cell bodies, subjected to laser micro-dissection. This method located parvalbumin neurons without immune histo chemical processing and provided intact RNA [29]. Since neuronal cells are big in size, it was possible to compare immune positive cells profile of one section to the serial section. Utility of this alternative method to identify cells of interest among the other tissue needed to evaluate. Molecular signature of glioma has been investigated where invading glioma tissue were harvested from rim of tumour cells mass [31-33]. These studies investigated gene signature of glioblastoma of brains. However, these studies do not emphasize on the role of tissue microenvironment on development of glioblastoma. Microenvironment plays an important role in orchestrating invasion of cancerous cells into normal tissue. Laser microdissection allows isolation of different types of tissue- glioma cancer cells, invading glioma cells and cells of normal cortex. This comprehensive type of tissue sampling permitted study of tumour microenvironment and gene regulatory networks and pathways responsive for glioma invasion [34].

Laser micro dissection can also be used to identify gene knockout cells at genomic level. Micro dissection of motor neurons from spinal cord for DNA isolation led identification of neuron specific ablation of Mtmr2 gene inknock out mice using PCR [35]. Identification of dopaminergic neurons from substantia nigra pars compacta using laser captured micro dissection determined transcriptional changes in aged-matched and young control individuals and revealed mitochondrial DNA deletions in substantia nigra neurons in ageing [36]. One of the causes for Parkinson's disease was the substantial degradation of somatic mitochondrial DNA in aged-matched individual. In addition to finding a reason to prevent loss of somatic mitochondrial DNA loss in the disease, pathway analysis of gene regulatory networks responsible for neuronal loss could result in therapeutic interventions of Parkinson's disease [36,24].

Underlying mechanisms of cell survival rheostat switch which controls dying or surviving cells after traumatic brain injury, was the result of single neuronal cell (injured vs healthy cells from adjacent area) isolation using laser micro dissection systems [37]. Degeneration of motor neurons in amyotrophic lateral sclerosis has identified involvement of RNA binding proteins, TDP43 and FUS. The genes involved with these proteins are normally transcribed, evidenced by RNA sequencing of motor neurons of mutant vs. wild-type mice [38] that were purely isolated using laser micro dissection. Molecular basis of diseases of nervous systems like Parkinson's disease or schizophrenia, where particular types of neurons are vulnerable for degeneration, can be studied in detail upon their isolation individually in pure form [39].

\section{Muscle cells}

Skeletal muscle fibre is composed of various types of cells including microsatellite stem cells, neurons and vascular endothelium enabling molecular profiling of specific cell types at myofibril level difficult. Laser micro dissection systems offer expression profile of individual cell types like myofibrils, satellite stem cells, vascular elements and neuronal elements from muscle fibres [40-43]. Identification of type I, type IIA, type IIB and type IIC of myofibrils and then isolation of these different types of myofibrils using laser micro dissection provided insight in understanding the biology of muscular atrophy [44].

Molecular signature of laser micro dissected smooth muscle cells resulted in identification of gene involved in diseases like asthma, atopic and hypoxia-induced hypertension [45-47]. Asthma and atopy are the respiratory tract diseases having similar symptoms except asthma obstructs airways whereas atopy does not. Out of one hundred differentially expressed genes between asthma and non-asthma (including atopy) patients, a set of eight genes distinguished asthmatic from non-asthmatic patients [47].

\section{Cancer cells}

Cancer tissues are well known for tissue heterogeneity having different types of tissues e.g., healthy cells, cancerous cells, invasive cancerous cells, infiltrating immune cells, proliferating cells of blood vessels and surrounding stroma (Figure 2). Breast carcinoma, for example, is a mixture of different cells types as revealed by molecular analysis of the tissue [48-50]. Because of such heterogeneity of tissues, the RNA or protein isolated from cancer tissues actually represents transcripts or proteins 
of various cell types present in the cancerous tissue under examination. Thus, pool of transcripts or protein derived from various cell types of tumour, prohibits prognostic discovery of cell-specific markers and drug discovery. Isolation of primary breast tissue and corresponding metastatic lymph nodes using laser micro dissection provided insights of metastatic progression of breast cancer [51].

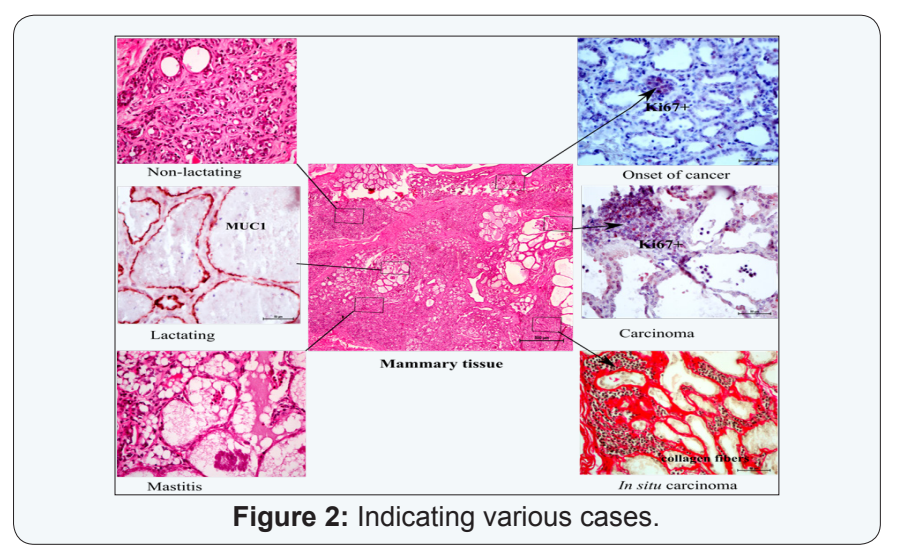

Protocol of performing staining, micro dissection of cancer specific cells from heterogeneous mixture of breast tumours, protein isolation from micro dissected cells and protein biomarker discovery using mass spectrophotometric are provided from frozen tissue (Braakman et al. 2011)[52]. Microenvironment often drives cells for normal or abnormal phenotypes. In breast cancer, understanding stromal component of tumour thus offers promise to understand tumour-associated changes. Isolation of tumour cells and stromal cells surrounding cancer cells using laser micro dissection offered study of tumour associated microenvironments [53]. Proteomic analysis of different stages of colorectal cancers, it was found that tenascin-C was a potential stromal biomarker for colorectal cancer metastasis [54]. It was a combined methodology of LCM, ITRAQ labelling and liquid chromatography-tandem mass spectrometry (2D LC-MS/MS) of stromal proteins from various stages of colorectal cancer.

Potential markers (AnnexinA2, HSP27, CK19 and 14-3-3б) of lymph node metastasis of lung squamous cell carcinoma identified using 2D-gel electrophoresis of laser captured micro dissected cell in human lungs. Such differentially expressed proteins may serve as protein biomarker of metastatic lung squamous cell carcinoma and provides molecular basis of metastasis that might provide a way for predictive diagnosis and outcome of patient's treatment [55]. A proteomic profiling of various types of lung adenocarcinomas using LMD identified 840 proteins in which early lepidic-types of lung adenocarcinomas was associated with numerous tumour progression pathways [56].

Combination of LCM and mass spectrophotometry revealed 14-3-3-mediated signalling pathways as the most relevant canonical pathway of colorectal cancer [56]. Likewise, proteomic study of LCM islets, LCM acinar tissue and EIC islets proteomes enabled accurate and unbiased profiling of islet proteome. Such studies could enable study of progression of type1 diabetes of pancreas and progression of other diseases where heterogeneous types of cells are involved [57]. Thus, laser micro dissection offers a reliable method to enrich specific cell population for proteome analysis. Proteome profiling of 38 breast cancer tissues in which, comparison of whole cell lysates and LCM enriched tumour epithelial cells were compared, identified more number of proteins in captured epithelial cells [58]. LCM and LMD also overcome limitation of working with small sample size such as the early lesion of cancer of frozen or formalin fixed paraffin embedded tissue sections [59]. Thus, laser micro dissection disregards influence of tissue heterogeneity, low interference from surrounding tissue and offers a better tool for biomarker discovery in meagre of sample.

\section{Microorganisms}

Less known application of laser micro dissection is the isolation and characterization of selective microorganisms from biological samples. Bart De Spiegeleer and colleagues [60] described selective isolation of microorganisms from milk using laser capture micro dissection. Investigators have identified Methylobacterium spp. using DNA sequencing of 16SrRNA gene. Phylogenetic identification of unidentified and uncultured microorganisms has been done reliably on the basis of ribosomal RNA sequence [61,62]. Likewise, a combined approach of fluorescent in situ hybridization and laser capture micro dissection has identified Brachyspira spp from human gut. Bacteria were targeted with oligo nucleotide probe against 16S RNA in paraffin embedded formalin fixed tissue sections, fluoresced green and regions of interest were micro dissected for DNA sequencing [63].

Use of LCM to harvest Lawsonia intracellularis infected pigs enterocytes has enabled investigator to characterize host-bacterial interactions. With the help of RNA sequencing of bacterial infected enterocytes, it was shown that bacteria prevent differentiation of enterocytes by repressing membrane transporters related nutrient uptake and prevented themselves from oxidative stress by utilizing host's $\mathrm{Zn} / \mathrm{cu}$ superoxide dismutase machinery [64]. In a recent study, LCM successfully used to harvest intracellular malarial parasites from avian erythrocytes for whole genome sequencing [65]. LCM offer investigator to isolate parasitic DNA without contamination of host DNA. Thus, LCM might offer isolation of individual parasites from co-infected hosts and also help in isolation of rear species of parasites from museum/achieved samples [65].

\section{Molecular profiling of immune-selected cells}

In majority of the situations, precise identification of phenotypically similar but immune phenotypically dissimilar cell types are not useful by standard histo chemical staining procedures. Only immune staining with immune specific markers offer unequivocal identification of precise cell types. Mammary stem/progenitor cells of bovine mammary gland have been identified using bromodeoxy uridine (BrdU) label retention 
study in which BrdU label retaining epithelial cells (LREC) were micro dissected and expression study were performed using microarray analysis [13]. In this study, LREC (mammary stem/progenitor cells) and non-LREC (differentiated cells from adjacent locations as control cells) were harvested using laser micro dissection and total RNA isolated. Microarray analysis revealed up-regulation of stem cells related genes in LREC in comparisons to non-LREC, provided the evidence of LREC as putative stem/progenitor cells. Immuno staining protocol using glial fibrillary acidic protein marker permitted precise and accurate identification of astrocytes and enabled expression analysis of laser micro dissected astrocytes using quantitative PCR [66].

To understand biology of different cells of pancreas namely, $\beta$-cells, alpha-cells and islets, laser micro dissections employed in normal and pathological conditions to harvest cells of interest. Isolating $\beta$-cells of pancreas by identifying fluorescence of antiinsulin antibody has enriched $\beta$-cells isolation by LCM $[67,68]$. This protocol prevented contamination of isolated cells from exocrine cells of pancreas. Protocols for obtaining pancreatic $\beta$-cells [69] and pancreatic duct glands [70] for transcriptome analysis have been proposed. Immuno-selected specific cells could also use for comprehensive protein profiling. In human pancreatic adenocarcinoma cells, CD24+ cells were micro dissected and protein profiles were compared with adjacent normal tissue that were CD24- cells [71]. In this study, investigators have discovered 27 candidate proteins expressed significantly different in CD24+ cells than normal tissue and suggested these proteins as potential biomarkers for pancreatic cancers as potential therapeutic targets.

\section{Expression micro dissection (xMD)}

It is an immune-based cell or sub cellular isolation tool when combined with laser micro dissection system provides rapid procurement of target of interest from cytological/histological tissue samples. This is very useful in where immune positive cells are harvested from the tissue section with increased speed of dissection in multiple magnitude [72,73]. In one recent study, tumour cells with estrogen receptor-positive nuclei harvested for large region of tissue in contiguous fashion thus offered precise sub cellular dissection of targets [74]. In cancer research, this tool is going to provide information of neoplastic transformation of cells from normal to cancer type. It has been observed that within the same tissue section, various types of tissues are found (Figure 2). Especially in carcinoma, where cells are invasive carcinoma, hyperplasia, partially transformed cells to normal healthy cells is present. xMD is going to offer enrichment of scanty cells from admixture of cell population including pathogens for next generation sequencing, proteomics and genomics study.

\section{Limitations of laser micro dissection system}

Major consideration during immune staining and laser micro dissection of tissue or cells is the integrity of RNA for gene expression analysis and quality of protein for protein analysis. Reduction in immune staining protocol by short incubation time, maintaining RNase free environment by addition of RNase inhibitor and nuclease free water and buffers are imperative for successful isolation of intact RNA. In addition to that, testing of RNA quality using standard procedures like Nano Drop reading and RNA denaturing gel electrophoresis to visualize $28 \mathrm{~S}$ and $18 \mathrm{~S}$ band might not be applicable as the quantity of RNA is so meagre. Only capillary-based electrophoresis system like Agilent bioanalyzer or Bio Rad experion systems could determine quantity of RNA in nano- and pico-grams and quality in terms of RNA integrity number.

Working with limited amount of RNA introduces problems related to signal to noise ratio in gene expression analysis. Quantity of RNA obtained from laser micro dissected cells range between nano- to pico-grams and the amount of RNA needed for microarray or RNA sequencing is in microgram. Therefore, it is required to amplify total RNA from pico- to micro-gram quantity. Various techniques exists to amplify picogram of RNA into microgram quantity that are required for expression analysis [75] indicating that it is feasible and reliable to accurately perform expression profiling of sub-optimal quantity of RNA.

Another limitation is the ineffective isolation of homogenous cell types due to lack of distinct cell types of haematoxylin stained sections. Adoption of immune histo chemical staining prior to LCM will assist researchers for immune phenotypic identification of cells within tissue. In such cases, identified cells are dead in nature and hence could not be propagated to test their characteristics and also studying of expression dynamics of the immune stained protein is limited due to binding of antibody with the protein of interest. Another limitation of laser micro dissection is that a skilful person and therefore, it usually identify various cell types of tissue could cyto architecture of tissue of interest should be known to the investigators [76].

\section{Conclusion}

Laser micro dissection system is a powerful and useful tool in many areas of biological and medical research. The technique is now able to produce meaningful, accurate and reproducible biology at cellular and molecular level. In cell biology, it is used in neuroscience research to study various types of nerve cells. In cancer biology, laser micro dissection is used for study the microenvironment of cancer cells, biology of various cell types and cancer metastasis. Profiling of various cell types within epithelial and stromal compartment of mammary tissue is helpful in delineating their molecular phenotypes. Isolation of microorganisms from tissue is a novel research towards understanding host-pathogen interactions and hence sheds light into progression of the disease.

Laser micro dissection could be the most beneficial and advantageous tool in the context that the area of transcriptomics and proteomics of selective cells with almost nil contamination of other cell types. It would be interesting to see advancement in 
this technique to isolate live cells so that isolated cells would be suitable for studying cell kinetics and propagation. Additionally, isolation of cell organelles, low cost system and high throughput micro dissection like expression micro dissection system (xMD) would like help in studying progress of neoplastic transformation of cells and their microenvironments.

\section{Acknowledgment}

Author would like to thank Department of Biotechnology, New Delhi (project reference number BT/AAQ/01/AB-I/TFAP/2014) for fund. Author would also like to thank USDA, Beltsville lab during which author gets the expertise of handling laser micro dissection under the guidance of Dr. Anthony Capuco. Author would like to acknowledge Dr Devendra Pathak for helping in capturing microscopic images (Figure 2).

\section{References}

1. Fend F, Kremer M, Quintanilla-Martinez L (2000) Laser capture microdissection: methodical aspects and applications with emphasis on immuno-laser capture micro dissection. Pathobiology 68(4-5): 209214.

2. Curran S, McKay JA, McLeod HL, Murray GI (2000) Laser capture microscopy. Mol Pathol 53(2): 64-8.

3. Fend F, Emmert-Buck MR, Chuaqui R, Cole K, Lee J, et al (1999) ImmunoLCM: laser capture micro dissection of immuno stained frozen sections for mRNA analysis. Am J Pathol 154(1): 61-66.

4. Kaneko T, Cordeiro MMR, Okiji T, Kaneko R, Suda H, et al. (2010) Laser capture microdissection from formaldehyde-fixated and demineralized paraffin embedded tissues. Microscopy: Science, Technology, Applications and Education. pp 2111-2116.

5. Burgemeister R (2011) Laser capture micro dissection of FFPE tissue sections bridging the gap between microscopy and molecular analysis. Methods Mol Biol 724: 105-15.

6. Bevilacqua C, Makhzami S, Helbling JC, Defrenaix P, Martin P (2010) Maintaining RNA integrity in a homogeneous population of mammary epithelial cells isolated by Laser Capture Micro dissection. BMC Cell Biol 11: 95.

7. McGinley JN, Zhu Z, Jiang W, Thompson HJ (2010) Collection of epithelial cells from rodent mammary gland via laser capture microdissection yielding high-quality RNA suitable for microarray analysis. Biol Proced Online 12: 31-43.

8. Daniels KM, Choudhary RK, Evock-Clover CM, et al (2011) Comparitive transcriptome analysis of laser micro dissected cells from bovine mammary gland.

9. Casey T, Dover H, Liesman J, DeVries L, Kiupel M, et al. (2011) Transcriptome analysis of epithelial and stromal contributions to mammogenesis in three week prepartum cows. PLoS One 6(7): e22541.

10. Velayudhan BT, Mcgilliard ML, Jiang H, et al (2013) Gene expression profile in prepubertal bovine mammary parenchyma and epithelial cells in response to ovariectomy. j Vet Anim Sci 44: 8-14.

11. Choudhary RK, Daniels KM, Evock-Clover CM, Garrett W, Capuco AV, et al. (2010) Technical note: A rapid method for 5-bromo-2'-deoxyuridine (BrdU) immunostaining in bovine mammary cryosections that retains RNA quality. J Dairy Sci 93(6): 2574-9.

12. Choudhary RK, Li RW, Evock-Clover CM, Capuco AV (2013) Comparison of the transcriptomes of long-term label retaining-cells and control cells microdissected from mammary epithelium: an initial study to characterize potential stem/progenitor cells. Front Oncol 3: 21.
13. Brenaut P, Lefèvre L, Rau A, Laloe D, Pisoni G, et al. (2014) Contribution of mammary epithelial cells to the immune response during early stages of a bacterial infection to Staphylococcus aureus. Vet Res 45(1): 16.

14. Cánovas A, Rincón G, Bevilacqua C, Islas Trejo A, Brenaut P, et al. (2014) Comparison of five different RNA sources to examine the lactating bovine mammary gland transcriptome using RNA-Sequencing. Sci Rep 4: 5297.

15. Marioni JC, Mason CE, Mane SM, Stephens M, Gilad Y (2008) RNA-seq: an assessment of technical reproducibility and comparison with gene expression arrays. Genome Res 18(9): 1509-17.

16. Zhao S, Fung-Leung W-P, Bittner A, Ngo K, Liu X (2014) Comparison of RNA-Seq and microarray in transcriptome profiling of activated $\mathrm{T}$ cells. PLoS One 9(1): e78644.

17. Iyer EPR, Iyer SC, Sulkowski MJ, Cox DN (2009) Isolation and purification of Drosophil peripheral neurons by magnetic bead sorting. J Vis Exp 34: e1599.

18. Huynh HT, Robitaille G, Turner JD (1991) Establishment of bovine mammary epithelial cells (MAC-T): an in vitro model for bovine lactation. Exp Cell Res 197(2): 191-9.

19. Kawahara Y, Kwak S, Sun H, Ito K, Hashida H, et al. (2003) Human spinal motoneurons express low relative abundance of GluR2 mRNA: an implication for excitotoxicity in ALS. J Neurochem 85(3): 680-689.

20. Elstner M, Morris CM, Heim K, Lichtner P, Bender A, et al. (2009) Singlecell expression profiling of dopaminergic neurons combined with association analysis identifies pyridoxal kinase as Parkinson's disease gene. Ann Neurol 66(6): 792-8.

21. Brown AL, Smith DW (2009) Improved RNA preservation for immunolabeling and laser microdissection. RNA 15(12): 2364-74.

22. Iyer EPR, Cox DN (2010) Laser capture microdissection of Drosophila peripheral neurons. J Vis Exp 39: 2016.

23. Hideyama T, Yamashita T, Suzuki T, Tsuji S, Higuchi M, et al. (2010) Induced loss of ADAR2 engenders slow death of motor neurons from Q/R site-unedited GluR2. J Neurosci 30(36): 11917-25.

24. Elstner M, Morris CM, Heim K, Bender A, Mehta D, et al. (2011) Expression analysis of dopaminergic neurons in Parkinson's disease and aging links transcriptional dysregulation of energy metabolism to cell death. Acta Neuropathol 122(1): 75-86.

25. Hideyama T, Teramoto S, Hachiga K, Yamashita T, Kwak S (2012) Cooccurrence of TDP-43 mislocalization with reduced activity of an RNA editing enzyme, ADAR2, in aged mouse motor neurons. PLoS One 7(8): e43469.

26. Tagliafierro L, Bonawitz K, Glenn OC, Chiba-Falek O (2016) Gene Expression Analysis of Neurons and Astrocytes Isolated by Laser Capture Microdissection from Frozen Human Brain Tissues. Front Mol Neurosci 9:72.

27. Murakami H, Liotta L, Star RA (2000) IF-LCM: laser capture micro dissection of immuno fluorescently defined cells for mRNA analysis rapid communication. Kidney Int 58(3): 1346-53.

28. Smolinski D, Blessenohl M, Neubauer C, Kalies K, Gebert A (2006) Validation of a Novel Ultra-Short Immuno labeling Method for HighQuality mRNA Preservation in Laser Microdissection and Real-Time Reverse Transcriptase-Polymerase Chain Reaction. J Mol Diagnostics 8(2): 246-253.

29. Kase M, Houtani T, Sakuma S, Tsutsumi T, Sugimoto T, et al. (2007) Laser micro dissection combined with immune-histo chemistry on serial thin tissue sections: a method allowing efficient mRNA analysis. Histochem Cell Biol 127:215-9.

30. Gründemann J, Schlaudraff F, Haeckel O, Liss B (2008) Elevated alpha-synuclein mRNA levels in individual UV-laser-micro dissected 
dopaminergic substantia nigra neurons in idiopathic Parkinson's disease. Nucleic Acids Res 36: e38.

31. Hoelzinger DB, Mariani L, Weis J, Woyke T, Berens TJ (2005) Gene expression profile of glioblastoma multiforme invasive phenotype points to new therapeutic targets. Neoplasia 7(1): 7-16.

32. Li A, Walling J, Ahn S, Kotliarav Y, Su Q et al. (2009) Unsupervised analysis of transcriptomic profiles reveals six glioma subtypes. Cancer Res 69(5): 2091-9.

33. Kislin KL, McDonough WS, Eschbacher JM, et al (2009) NHERF-1: modulator of glioblastoma cell migration and invasion. Neoplasia 11(4): 377-87.

34. Nevo I, Woolard K, Cam M, et al (2014) Identification of molecular pathways facilitating glioma cell invasion in situ. PLoS One 9:e111783.

35. Bolis A, Coviello S, Bussini S, et al (2005) Loss of Mtmr2 phosphatase in Schwann cells but not in motor neurons causes Charcot-Marie-Tooth type 4B1 neuropathy with myelin outfoldings. J Neurosci 25(37): 8567-77.

36. Bender A, Krishnan KJ, Morris CM, Taylor GA, Reeve AK, et al. (2006) High levels of mitochondrial DNA deletions in substantia nigra neurons in aging and Parkinson disease. Nat Genet 38: 515-7.

37. Boone DR, Sell SL, Hellmich HL (2013) Laser capture micro dissection of enriched populations of neurons or single neurons for gene expression analysis after traumatic brain injury. J Vis Exp (74): 50308.

38. Bandyopadhyay U, Cotney J, Nagy M, et al (2013) RNA-Seq profiling of spinal cord motor neurons frBandyom a presymptomatic SOD1 ALS mouse. PLoS One 8:e53575.

39. Grison A, Zucchelli S, Urzì A, Zamparo I, Lazarevic D, et al. (2014) Mesencephalic dopaminergic neurons express a repertoire of olfactory receptors and respond to odorant-like molecules. BMC Genomics 15(1): 729.

40. Dalmas DA, Scicchitano MS, Chen Y, Kane J, Mirabile R, et al. (2008) Transcriptional profiling of laser capture micro dissected rat arterial elements: fenoldopam-induced vascular toxicity as a model system. Toxicol Pathol 36(3): 496-519.

41. Huang ZS, Malek JY, Bhasin M (2009) Selective isolation of vein graft endothelial and smooth muscle cells using laser capture micro dissection for microarray gene analysis. FASEB J 23:LB322-.

42. Greenberg SA, Salajegheh M, Judge DP, Feldman MW, Kunci RW, et al (2012) Etiology of limb girdle muscular dystrophy 1D/1E determined by laser capture microdissection proteomics. Ann Neurol 71(1): 141-5.

43. Ikeda A, Kai H, Kajimoto H, Yasuoka S, Kage Masayoshi, et al (2012) Selective gene expression analysis of muscular and vascular components in hearts using laser microdissection method. Int J Vasc Med 2012: 863410 .

44. Vanderburg CR, Clarke MS (2013) Laser capture micro dissection of metachromatically stained skeletal muscle allows quantification of fiber type specific gene expression. Mol Cell Biochem 375(1-2): 15970 .

45. Kwapiszewska G, Wilhelm J, Wolff S, Laumanns I, Koenig IR, et al. (2005) Expression profiling of laser-micro dissected intrapulmonary arteries in hypoxia-induced pulmonary hypertension. Respir Res 6(1): 109.

46. Fink L, Kwapiszewska G, Wilhelm J, Bohle RM (2006) Lasermicrodissection for cell type- and compartment-specific analyses on genomic and proteomic level. Exp Toxicol Pathol 57 (Suppl 2): 25-9.

47. Yick CY, Zwinderman AH, Kunst PW, GrunbergK, Mauad T, et al. (2014) Gene expression profiling of laser microdissected airway smooth muscle tissue in asthma and atopy. Allergy 69(9): 1233-40.
48. Wild P, Knuechel R, Dietmaier W, et al (2000) Laser micro dissection and microsatellite analyses of breast cancer reveal a high degree of tumor heterogeneity. Pathobiology 68:180-90.

49. Stingl J, Caldas C (2007) Molecular heterogeneity of breast carcinomas and the cancer stem cell hypothesis. Nat Rev Cancer 7: 791-9.

50. Polyak K (2011) Heterogeneity in breast cancer. J Clin Invest 121(10): 3786-8.

51. Ellsworth RE, Seebach J, Field LA, Heckman C, Kane J, et al. (2009) A gene expression signature that defines breast cancer metastases. Clin Exp Metastasis 26(3): 205-13.

52. Braakman RB, Luider TM, Martens JW, Foekens JA, Umar A (2011) Laser capture micro dissection applications in breast cancer proteomics. Methods Mol Biol 755:143-54.

53. Bertos NR, Park M (2016) Laser Capture Micro dissection as a Tool to Study Tumor Stroma. Methods Mol Biol 1458: 13-25.

54. Zhang Y, Liu Y, Ye Y, et al (2016b) Quantitative proteome analysis of colorectal cancer-related differential proteins. J Cancer Res Clin Oncol.

55. Yao H, Zhang Z, Xiao Z, Chen Yongheng, Li C, et al (2009) Identification of metastasis associated proteins in human lung squamous carcinoma using two-dimensional difference gel electrophoresis and laser capture micro dissection. Lung Cancer 65(1): 41-8.

56. Kato Y, Nakamura H, Tojo H, Nomura M, Nagao T (2015) A proteomic profiling of laser-micro dissected lung adenocarcinoma cells of early lepidic-types. Clin Transl Med 4: 24.

57. Zhang L, Lanzoni G, Battarra M, Inverardi L, Zhang Q et al. (2016a) Proteomic profiling of human islets collected from frozen pancreata using laser capture microdissection. J Proteomics 150: 149-159.

58. De Marchi T, Braakman RB, Stingl C, Van Duijn MM, Smid M, et al. (2016) The advantage of laser-capture micro dissection over whole tissue analysis in proteomic profiling studies. Proteomics 16(10): 1474-85.

59. Longuespée R, Alberts D, Pottier C, Smargiasso N, Mazzucchelli G, et al. (2016) A laser micro dissection-based workflow for FFPE tissue micro proteomics: Important considerations for small sample processing. Methods 104:154-62.

60. Bracke N, Van Poucke M, Baert B, Wynendaele E, Bels LD, et al. (2014) Identification of a microscopically selected microorganism in milk samples. J Dairy Sci 97(2): 609-15.

61. Olsen GJ, Lane DJ, Giovannoni SJ, Pace NR, Stahl DA (1986) Microbial ecology and evolution: a ribosomal RNA approach. Annu Rev Microbiol 40: 337-65.

62. Schmidt TM, Relman DA (1994) Phylogenetic identification of uncultured pathogens using ribosomal RNA sequences. Methods Enzymol 235: 205-22.

63. Klitgaard K, Mølbak L, Jensen TK, Lindboe CF, Boye M (2005) Laser capture micro dissection of bacterial cells targeted by fluorescence in situ hybridization. Biotechniques 39(6): 864-8.

64. Vannucci FA, Foster DN, Gebhart CJ (2013) Laser micro dissection coupled with RNA-seq analysis of porcine enterocytes infected with an obligate intracellular pathogen (Lawsonia intracellularis). BMC Genomics 14:421.

65. Lutz HL, Marra NJ, Grewe F, Carlson JS, Palinauskas V, et al. (2016) Laser capture micro dissection microscopy and genome sequencing of the avian malaria parasite, Plasmodium relictum. Parasitol Res 115(12): 4503-4510.

66. 66.Burbach GJ, Dehn D, Nagel B, Turco DD, Deller T (2004) Laser microdissection of immunolabeled astrocytes allows quantification of astrocytic gene expression. J Neurosci Methods 138: 141-8. 
67. Marselli L, Thorne J, Ahn Y-B, Omer A, Sqroi DC, et al. (2008) Gene expression of purified beta-cell tissue obtained from human pancreas with laser capture micro dissection. J Clin Endocrinol Metab 93(3): 1046-53.

68. Marselli L, Sgroi DC, Bonner-Weir S, Weir GC (2009) Laser capture micro dissection of human pancreatic beta-cells and RNA preparation for gene expression profiling. Methods Mol Biol 560: 87-98.

69. Sturm D, Marselli L, Ehehalt F, Richter D, Distler M, et al. (2013) Improved protocol for laser micro dissection of human pancreatic islets from surgical specimens. J Vis Exp 71: 50231.

70. Butler AE, Matveyenko AV, Kirakossian D, Park J, Gurlo T, et al. (2016) Recovery of high-quality RNA from laser capture micro dissected human and rodent pancreas. J Histotechnol 39(2): 59-65.

71. Zhu J, Nie S, Wu J, Lubman DM (2013) Target proteomic profiling of frozen pancreatic CD24+ adenocarcinoma tissues by immuno-laser capture microdissection and nano-LC-MS/MS. J Proteome Res 12(6): 2791-804.
72. Hanson JC, Tangrea MA, Kim S, Armani MD, Pohida TJ, et al. (2011) Expression micro dissection adapted to commercial laser dissection instruments. Nat Protoc 6(4): 457-67.

73. Tangrea MA, Mukherjee S, Gao B, Markey SP, Du Q, et al. (2011) Effect of immunohistochemistry on molecular analysis of tissue samples: implications for micro dissection technologies. J Histochem Cytochem 59(6): 591-600.

74. Rosenberg AZ, Armani MD, Fetsch PA, Xi L, Pham TT, et al. (2016) Highthroughput micro dissection for next-generation sequencing. PLoS One 11(3):1-13.

75. Lang JE, Magbanua MJM, Scott JH, Makrigiorgos GM, Wang G, et al. (2009) A comparison of RNA amplification techniques at subnanogram input concentration. BMC Genomics 10: 326.

76. Jensen E (2013) Laser-Capture Micro dissection. Anat Rec 296(11): 1683-1687.

Your next submission with JuniperPublishers will reach you the below assets

- Quality Editorial service

- Swift Peer Review

- Reprints availability

- E-prints Service

- Manuscript Podcast for convenient understanding

- Global attainment for your research

- Manuscript accessibility in different formats

( Pdf, E-pub, Full Text, Audio)

- Unceasing customer service

Track the below URL for one-step submission

https://juniperpublishers.com/online-submission.php 